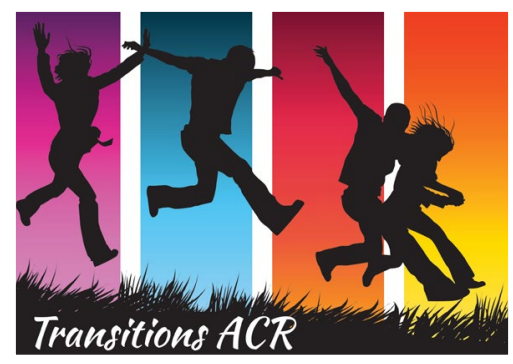

\title{
WORKING FROM HOME DURING THE COVID-19 PANDEMIC: TIPS AND STRATEGIES TO MAINTAIN PRODUCTIVITY \& CONNECTEDNESS
}

Vol 17 Issue 5

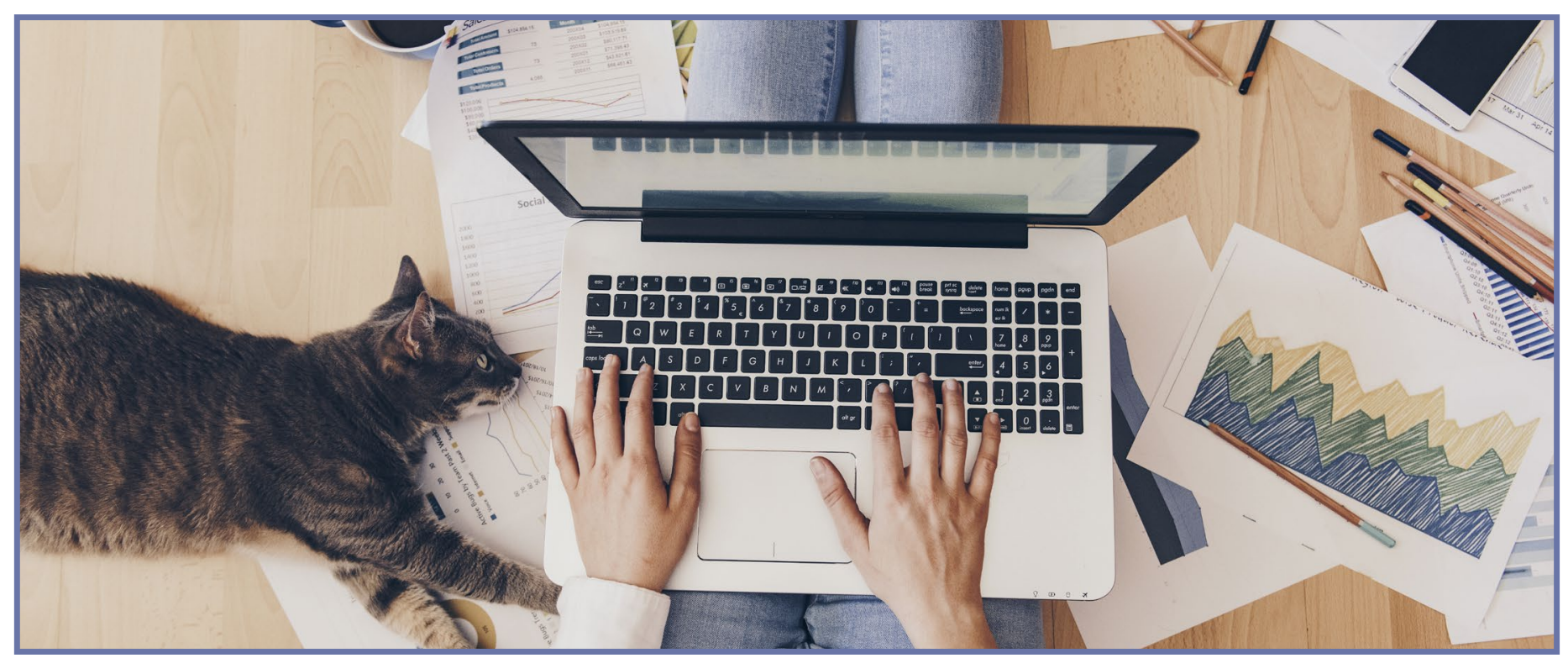

IN THE WAKE of the global COVID-19 pandemic ${ }^{1}$ now spreading across the United States, ${ }^{2}$ a lot of changes are happening within the workforce. These changes have probably resulted in lots of adjustments for you, your family and those you work closely with. Of the many changes we are currently facing, one of them is the new request that many workers shift from coming into their workplace to working from home.

On March 16, 2020, the White House officially recommended anyone able to work from home should do so. As such, many of us are now working remotely; something few of us are used to doing for long stretches of time. At first, the idea of working from home can seem appealing, and even fun-who doesn't love the idea of wearing PJs to work? However, successfully working from home can present unique challenges, from how to focus with at-home distractions, to trying to be productive and communicate well with team members from afar.

Here at the Transitions to Adulthood Center for Research, many of our faculty and staff have years of experience mastering the art of remote work and have put together a list of their top 5 tips and tricks to navigating this strange new world. We know these times are unique and there is a lot of stress and fear around COVID-19, so managing working from home under these conditions is a bit different, but the following strategies may help you find some new ways of maintaining productivity, while still allowing time for Netflix, pets, family and other ways to help you destress!

\section{Communicate openly and often with project supervisors} and allow for flexibility when necessary.

\section{MAINTAIN STRONG AND CONSISTENT CONNECTIONS WITH YOUR SUPERVISORS}

Whoever is normally responsible for overseeing your daily duties should be looped into your tasks and timelines, as well as to your struggles and successes. This will help keep you on track and feeling supported.

\section{BALANCING UPDATES AND E-MAIL OVERLOAD}

Casual conversation at the office has been replaced by e-mails and texts. Work with your supervisor to figure out how to balance chit-chat, the increase in

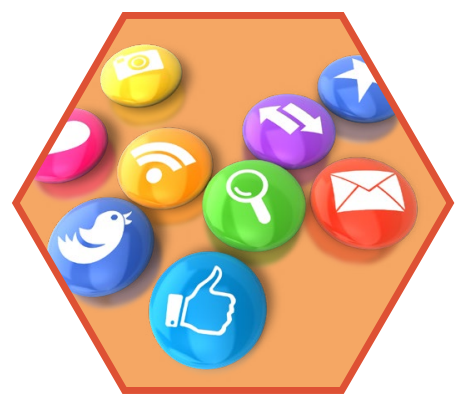


e-mails, and work tasks. One way to combat this, if possible, is to only check your e-mail three times a day (morning, mid-day, and afternoon). ${ }^{3,4}$ Discuss how to minimize e-mail distractions with the people to whom you report and anyone who reports to you. ${ }^{3,4}$ Explain that by reducing the total number of interruptions in a day, the more able you are to focus on completing tasks. ${ }^{3-5}$

\section{MANAGING UP}

Ask for what you need from managers, ask for what they need, and agree on what you can reasonably do given the circumstances. Be clear about due dates, priorities, and expectations. Your boss may also be distracted by managing other COVID-19 related issues, so bring any questions you have to them.

\section{PRIORITIZE, PRIORITIZE, PRIORITIZE}

Identify what's important, what's urgent, and what's neither, and then explore how to best manage those items together. After you agree, send an e-mail so that it is in writing.

PLAN AHEAD

Consider the circumstances where you might need to use your vacation, sick, or FMLA time and plan accordingly when possible.

\section{Consider making good use of a user-friendly time- management app or external monitoring aid.}

\section{MANAGING ONE'S OWN TIME CAN BE DIFFICULT, BUT THERE ARE MANY HELPFUL AIDS THAT CAN KEEP US ORGANIZED AND ON TRACK WITH DEADLINES}

Of course, we should make good use of our e-mail calendars, but it is also helpful to use new apps and other non-traditional time-tracking aids. Visit https:// toggl.com/ for one example some of our staff have found helpful. There are also downloadable apps easily found online which can enforce good habits by strategically shutting down internet access, or to particular websites, such as Facebook and other social media sites. Many people find that setting timers on their phones or watches can also be helpful.

\section{BE FLEXIBLE WITH YOURSELF}

Respect that you may need to be even more flexible with your time and efforts than usual. (This is yet another reason to be in more frequent contact with your supervisor, to keep them updated and help you adjust your schedule as needs arise.)

\section{Separate out work hours and personal time.}

\section{BREAK OUT WORK TIME AND PERSONAL TIME}

It is helpful to differentiate work time from personal time, so some distance can be put between when you are "at work" and when you are "at home." This is not an easy thing to do, but it can be done, if you stick to a schedule which is reasonable and personalized.

\section{SET HEALTHY WORK BOUNDARIES}

It is also important to put boundaries on your work hours, to prevent the compulsion to work round the clock. When you are in the comfort of your home, it is easy to think it's okay to check e-mails at odd hours. Putting in strange and fragmented hours is problematic for a host of reasons, though, including that doing uncompensated work may contribute to resentment and burnout. Working all the time may also take an equally unnecessary toll on one's family. 


\section{Carve out a productive and dedicated workspace, similar to your office, that is separate from your living}

space.

\section{CRAFT A DESIGNATED SPACE FOR WORK AT HOME}

Time is not our only consideration. Differentiating workspaces from living spaces can also be important when working remotely. When you "go to work," you should be able to "leave" your living space and enter a new, productive space where you can accomplish work tasks and have online meetings with minimal disruption. Similarly, when you are done for the day, you will need to be able to decompress away from work.

\section{IDENTIFY IDEAL WORKSPACES WHERE YOU CAN DO YOUR BEST WORK}

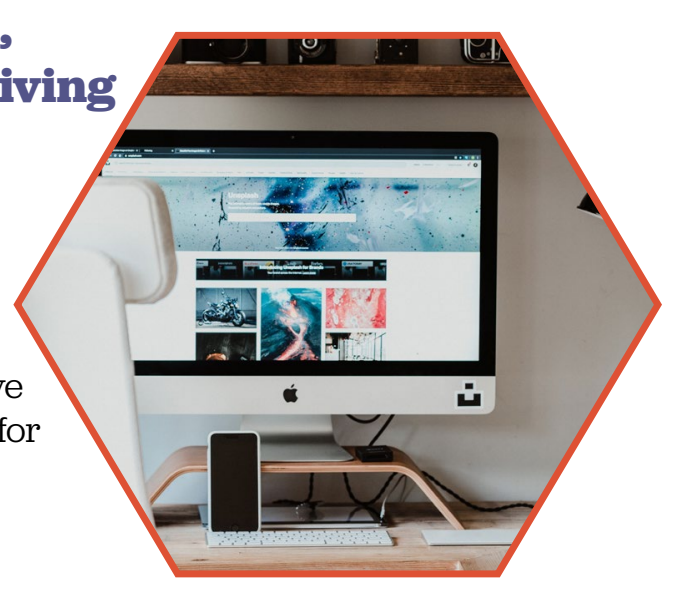

Although you need not reconstruct your office altogether, it can be helpful, for providing a sense of normalcy, to mold your new workspace into something like your office space. Setting yourself up for success sometimes means recreating the environment in which you are the most successful.

\section{STAYING PRODUCTIVE AT HOME}

Some of the things people find themselves doing while working from home are not work related, but are things that could have waited, like the dishes piling up in the sink. While these are important, they wouldn't have been as pressing if they weren't vying for attention in the middle of the day. This is another reason to avoid blending work time and personal time. Also important in maintaining a healthy level of productivity at work is to keep a de-cluttered workspace. It is challenging to stay organized mentally and emotionally if our workspaces are messy.

\section{Balancing caring for your children when you are expected to "work" from home.}

\section{COORDINATE SCHEDULES}

If you have children who are not yet independent, working from home during this time may be challenging. School closures place an ongoing demand on employees that can be hard to balance. If you have a partner at home, try to coordinate schedules so that you can alternate responsibilities throughout the day. Together, identify high priority meetings or tasks that require your attention and figure out who has kid-coverage during those times.

\section{WORK AROUND NAPS}

If your kids are small and still take regular naps, consider scheduling meetings during that time.

\section{WORK WITH CLIENTS AND COLLEAGUES TO CREATE SPACE BETWEEN MEETINGS}

Spacing meetings by 30-60 minutes allows you to check in with your children, play outside for a bit, or set them up with projects. This is also helpful for older, not yet independent children. These more frequent check-ins may reduce the need for them to "check-in" with you while on a conference call.

\section{CREATE A WORKSPACE FOR YOUR CHILDREN}

For older children, when possible, set up a schedule that mirrors yours, so your breaks and "working hours" align. Perhaps create an electronic calendar they can keep in their "workspace." This may help them develop their own time and task management skills.

\section{CREATING A “TO DO" LIST}

Waking up early, before your children, to create a to-do list, and getting important 
items done that need large amounts of focus may be a good idea. Conversely, if you are a night person, you can flip this suggestion to accommodate late-night attempts at quiet, focused work. But do not use this time to attend to tasks that can be completed while there is chaos in your home (e.g., e-mail).

\section{NO APOLOGIES NECESSARY}

Do not apologize if your child disrupts you on a work call. The disruption may be embarrassing or ill timed, but it is not yours or your child's fault, and peoples' reactions to you managing parenthood during these times is a reflection of them and not you. Instead of apologizing, try replacing the need to say something with "Thank you for being patient," or, if you have to put someone on a brief hold, say, "Thanks for waiting for me." Occasionally your child may have to sit on your lap for a meeting. Most people will understand and may even welcome it.

\section{BE KIND TO YOURSELF}

Learn every day about what works and what doesn't. Make adjustments as needed. Figure out how you can be both productive and a good parent at the same time. This will be one of the biggest personal and professional challenges you will undertake.

Although working from home during COVID-19 may be a challenge, we are confident you can acclimate to it. It may be helpful to revisit these five core strategies often, especially in the beginning.

\section{REFERENCES}

I. Rezabakhsh, A., Ala, A., \& Khodaei, S. H. (2020). Novel coronavirus (COVID-19): A new emerging pandemic threat. Journal of Research in Clinical Medicine, 8(1), 5. doi:10.34172/jrcm.2020.05.

2. United States Centers for Disease Control. (2020, March 26). Severe outcomes among patients with coronavirus disease 2019 (COVID-19) - United States, February 12-March 16, 2020. Morbidity and Mortality Weekly Report (MMWR), 69(12), 343-346. Retrieved from https://www.cdc.gov/mmwr/volumes $/ 69 / \mathrm{wr} / \mathrm{mm} 6912 \mathrm{e} 2 . \mathrm{htm}$ ? s_cid=mm6912e2_w

3. Newport, C. (2016). Deep work: Rules for focused success in a distracted world. Grand Central Publishing, Hachette Book Group.

4. Spira, J. B., \& Feintuch, J. B. (2005). The cost of not paying attention: How interruptions impact knowledge worker productivity. Report from Basex. Retrieved from https://iorgforum.org/wp-content/uploads/2011/06/CostOfNotPayingAttention.BasexReportl.pdf

5. Galluch, P. S., Grover, V., \& Thatcher, J. B. (2015). Interrupting the workplace: Examining stressors in an information technology context. Journal of the Association for Information Systems, 16(1, 2). Retrieved from https://aisel.aisnet. org/jais/voll6/issl/2

Special acknowledgements: Morgan Rao, Jean Wnuk, Ally Murray, Emily McCaffrey, Rachel Stone, Debbie Nicolellis, Teresa Conrado, Deirdre Logan, Padma Sankaran, Bailey Pridgen, Marsha L. Ellison, \& Maryann Davis

Recommended Citation: Lane, I. A., Mullen, M. G., \& Costa, A. (2020). Working from Home During the COVID-19 Pandemic: Tips and Strategies to Maintain Productivity \& Connectedness. Worcester, MA: University of Massachusetts Medical School, Department of Psychiatry, Implementation Science and Practice Advances Research Center (iSPARC), Transitions to Adulthood Center for Research.

The contents of this tip sheet were supported in part under grants with funding from the National Institute on Disability, Independent Living, and Rehabilitation Research, (NIDILRR), United States Departments of Health and Human Services (NIDILRR grant number 90RTEM0005, The Learning and Working Transitions RRTC). NIDILRR is a Center within the Administration for Community Living (ACL), Department of Health and Human Services (HHS). The contents of this tip sheet do not necessarily represent the policy of NIDILRR, ACL, or HHS and you should not assume endorsement by the Federal Government.

This publication can be made available in alternative formats upon request through TransitionsACR@umassmed.edu

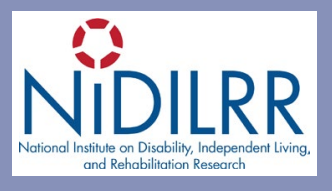

